\title{
ANALISIS PEMBIAYAAN PENCEGAHAN STUNTING DI KABUPATEN BADUNGDENGAN PENDEKATAN DISTRICT HEALTH ACCOUNT
}

\author{
Sugianto, Made Agus ${ }^{1 *}$, Rumiati, I Gusti Ayu Ngurah Lita ${ }^{2}$ \\ ${ }^{1,2}$ Badan Penelitian dan Pengembangan Kabupaten Badung \\ *Korespondensi: agusugianto146@gmail.com
}

\begin{abstract}
Background: Stunting rates in Badung Regency show an upward trend while information on funding and utilization and who is the beneficiary is still very limited. Therefore, through the District Health Account, it is expected that decision makers will be able to overcome the problem of adequacy, equity, efficiency, effectiveness and sustainability. Objective: to analyze the cost of stunting prevention using the District Health Account Approach. Method: This research is descriptive using cross-sectional studies, data collection through in-depth interviews to the manager of the District Health Office in Bandung District and the manager of the Provincial Health Department of Bali Nutrition and documentation studies. Results: Most stunting prevention costs came from the central government (70.16\%), and the highest proportion of the budget was managed by puskesmas $(56.74 \%)$. Most of the stunting prevention funding was used for operational expenditure (79.43\%), and the financing was mainly directed towards all age groups $(48.53 \%)$. In the lowest $40 \%$ (poor families) the average monthly expenditure is only Rp.438,944 or equivalent to $1,962.55 \mathrm{Kcal}$ per person per day, this figure is below the stipulated calorie adequacy rate of 2,200 - 2,500 Kcal per person per day. Conclusion: The cost of stunting prevention program is only sourced from the government, where most costs come from the central government $(70.16 \%)$, far exceeding the Badung Regency Government (21.16\%) and the Provincial Government of Bali (8.69\%). The cost of puskesmas stunting prevention program is used for operational expenses for the bottom $40 \%$ (poor families) whose average monthly expenditure is only equivalent to consuming $1,962.55 \mathrm{Kcal}$ of food per person per day. Badung Regency Government to increase the financing of stunting prevention which is prioritized for the lowest $40 \%$ population (poor population).
\end{abstract}

Keywords: Stunting; Financing; Badung Regency

\section{ABSTRAK}

Latar belakang: Angka stunting di Kabupaten Badung menunjukan tren peningkatan sedangkan informasi tentang pendanaan dan pemanfaatannya serta siapa penerima manfaatnya masih sangat terbatas. Oleh karena itu, melalui District Health Account diharapkan pengambil keputusan mampu mengatasi masalah kecukupan, pemerataan, efisiensi, efektivitas, dan keberlanjutan. Tujuan: untuk 
menganalisis pembiayaan pencegahan stunting dengan menggunakan dengan pendekatan District Health Account. Metode: penelitian ini bersifat deskriptif menggunakan studi crosssectional, Pengumpulan data melalui wawancara mendalam kepada pengelola program Gizi Dinkes Kab.Badung dan pengelola program Gizi Dinkes Prov.Bali dan studi dokumentasi. Hasil: Seluruh biaya pencegahan stunting terbanyak bersumber dari pemerintah pusat $(70,16 \%)$, dan proporsi anggaran terbanyak dikelola oleh puskesmas $(56,74 \%)$. Sebagian besar pembiayaan pencegahan stunting dipergunakan untuk belanja yang bersifat operasional $(79,43 \%)$, dan pembiayaan terutama diarahkan terutama pada semua kelompok umur $(48,53 \%)$. Pada kelompok masyarakat $40 \%$ terbawah (keluarga miskin) rata-rata pengeluaran per bulan hanya sebanyak Rp.438.944 atau setara dengan 1.962,55 Kcal per orang per hari, angka ini di bawah angka rata-rata kecukupan kalori yang ditetapkan yaitu $2.200-2.500 \mathrm{Kcal}$ per orang per hari. Simpulan: Biaya program pencegahan stunting hanya bersumber dari pemerintah, dimana biaya terbanyak bersumber dari pemerintah pusat $(70,16 \%)$, jauh melebihi Pemerintah Kabupaten Badung $(21,16 \%)$ dan Pemerintah Provinsi Bali (8,69\%). Biaya program pencegahan stunting puskesmas dipergunakan untuk belanja yang bersifat operasional untuk kelompok masyarakat $40 \%$ terbawah (keluarga miskin) yang rata-rata pengeluaran per bulan hanya setara dengan mengkonsumsi makanan sebanyak 1.962,55 Kcal per orang per hari. Pemerintah Kabupaten Badung agar meningkatkan pembiayaan pencegahan stunting yang diprioritaskan kepada penduduk $40 \%$ terbawah (penduduk miskin).

Kata kunci: Stunting; Pembiayaan; Kabupaten Badung

\section{LATAR BELAKANG}

Stunting adalah masalah gizi kronis yang disebabkan oleh asupan gizi yang kurang dalam waktu lama, umumnya karena asupan makan yang tidak sesuai kebutuhan gizi. Stunting terjadi mulai dari dalam kandungan dan baru terlihat saat anak berusia dua tahun. Menurut UNICEF, stunting didefinisikan sebagai persentase anak-anak usia 0 sampai 59 bulan, dengan tinggi di bawah minus dua (stunting sedang dan berat) dan minus tiga (stunting kronis) diukur dari standar pertumbuhan anak keluaran WHO (Dewi, 2017).

Organisasi Kesehatan Dunia (WHO) menempatkan Indonesia sebagai negara ketiga dengan angka prevalensi stunting tertinggi di Asia pada 2017. Hasil Riset Kesehatan Dasar (Riskesdas) 2018 menunjukan bahwa prevalensi Balita stunting turun dari 37,2\% pada tahun 2013 menjadi 23,6\% pada tahun 2018. Demikian pula di Provinsi Bali, angka stunting juga mengalami penurunan dari 
32,6\% pada tahun 2013 turun menjadi 21,8\% pada tahun 2018 (Kemenkes RI, 2019). Penurunan angka stunting menunjukan keberhasilan pelaksanaan program gizi, namun demikian angka ini masih di atas standar WHO yaitu maksimal 20 persen atau seperlima dari jumlah total anak balita (Novianto, 2019).

Berdasarkan data Dinas Kesehatan Provinsi Bali, angka stunting di Kabupaten Badung menunjukan tren peningkatan sepanjang tahun 2016 sampai dengan tahun 2018. Pada tahun 2015 angka stunting tercatat sebanyak 13,6\% lalu menurun menjadi 11,5\% pada tahun 2016. Memasuki tahun 2017 angka stunting kembali meningkat, dan hasil Riskesdas tahun 2018 mencatat angka stunting di Kabupaten Badung mencapai 25,24\% (Dinkes Prov. Bali, 2019).

Untuk mengatasi masalah stunting, Bupati Badung malakukan pencanangan Gerakan 1000 hari pertama kelahiran (Garba Sari) pencegahan stunting balita yang ditandai dengan pemberian bingkisan makanan tambahan kepada anak-anak dan ibu hamil. Di samping itu Pemerintah Kabupaten Badung juga menetapkan Peraturan Daerah Kabupaten Badung Nomor 13 Tahun 2017 tentang Anggaran Pendapatan dan Belanja Daerah Tahun Anggaran 2018 dengan mengalokasikan anggaran untuk pencegahan stunting sebanyak dari 514 juta rupiah (Pemkab Badung, 2019).

Tantangan ke depan adalah bagaimana agar para perencana di sektor kesehatan mampu menyusun perencanaan yang berbasis fakta. Sejauh ini proses perencanaan di Dinas Kesehatan menunjukkan bahwa informasi keuangan/pendanaan seperti sumber dana, pemanfaatannya serta siapa penerima manfaatnya sangatlah terbatas. Dengan tersedianya District Health Account tentu akan sangat membantu pengambil keputusan dalam menjawab beberapa pertanyaan pokok seperti isu kecukupan (sufficiency) pemerataan (equity), Efisiensi (efficiency), efektivitas (effectiveness) dan keberlanjutan (sustainability) yang dapat digunakan untuk kebijakan alokasi sumber daya kesehatan (Gani, A, 2009)

Secara umum penelitian ini bertujuan untuk menganalisis pembiayaan pencegahan stunting dengan menggunakan dengan Pendekatan District Health Account dan tujuan secara khusus adalah untuk mengetahui sumber, jenis belanja, 
pengelola dan penerima manfaat pembiayaan stunting sesuai mata anggaran District Health Account yang dikeluarkan oleh Kementerian Kesehatan.

\section{METODE}

Penelitian ini adalah penelitian deskriptif dengan desain studi crosssectional. Penelitian ini dilaksanakan di Kabupaten Badung selama dua bulan yaitu dari bulan Juni sampai Juli tahun 2019. Data sekunder dalam penelitian ini adalah seluruh anggaran bersumber pemerintah yang dibelanjakan dengan tujuan menurunkan angka stunting di Kabupaten Badung tahun 2018 (tidak termasuk gaji pegawai). Data kualitatif dalam penelitian ini adalah hasil wawancara dengan responden terkait proses perencanaan anggaran program pencegahan stunting. Instrumen district health acoount yang dipakai adalah klasifikasi account yang dikeluarkan oleh Pusat Pembiayaan dan Jaminan Kesehatan Kementrian Kesehatan Republik Indonesia pada tahun 2018.

\section{HASIL}

Belanja Kesehatan Program Pencegahan Stunting di Kabupaten Badung Tahun Anggaran 2018

Anggaran pembangunan kesehatan di Kabupaten Badung setiap tahun menunjukan tren peningkatan dengan peningkatan rata-rata sekitar $16,65 \%$. Secara lebih jelas jumlah anggaran setiap tahun dapat dilihat pada gambar 1 .

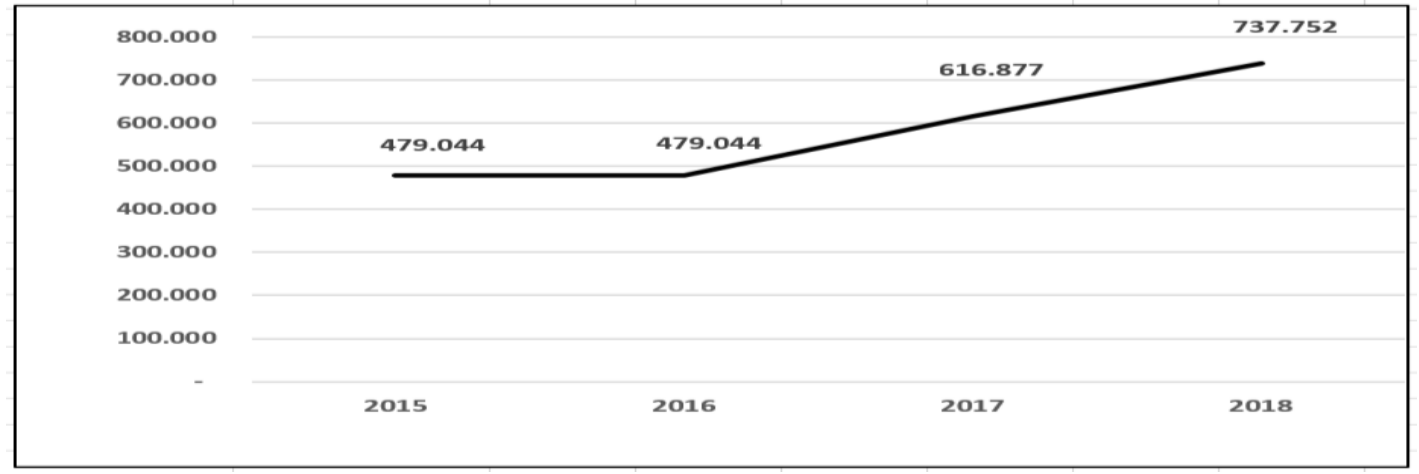

Gambar 1. Trend Anggaran Pembangunan Kesehatan di Kabupaten Badung Sumber: Data Dinas Kesehatan Kabupaten Badung Tahun 2019 
Total biaya program Pencegahan Stunting yang bersumber dari pemerintah baik pusat, provinsi maupun pemerintah Kabupaten kabupaten di Kabupaten Badung pada tahun 2018 sebesar Rp. 2.429.910.216. Secara proporsional, alokasi biaya tersebut, dapat dilihat pada Tabel 2.

Tabel 1 Sumber Pembiayaan Program Pencegahan Stunting di Kabupaten Badung Tahun 2018

\begin{tabular}{|c|c|c|}
\hline Sumber Pembiayaan (Fs) & Jumlah (n) & Presentase $(\%)$ \\
\hline FS 1.1.1. APBN Pusat & 1.704 .752 .400 & 70,11 \\
\hline FS 1.1.2. APBD Provinsi Bali & 211.090 .556 & 8,69 \\
\hline FS 1.1.3. APBD Kabupaten Badung & 514.067 .260 & 21,16 \\
\hline Total & 2.429 .910 .216 & 100,00 \\
\hline
\end{tabular}

Sumber: Data Dinas Kesehatan Kabupaten Badung Tahun 2019.

Tabel 1 menunjukan bahwa biaya program pencegahan stunting hanya bersumber dari pemerintah. Biaya terbanyak bersumber dari pemerintah pusat (70,11 \%), jauh melebihi Pemerintah Kabupaten Badung $(21,16 \%)$ dan Pemerintah Provinsi Bali $(8,69 \%)$. Adapun pengelola pembiayaan pencegahan stunting terlihat pada tabel 2

Tabel 2 Analisa Belanja Kesehatan Program Pencegahan Stunting Menurut Penyedia Pelayanan Tahun Anggaran 2018

\begin{tabular}{ccc}
\hline Pengelola Pembiayaan & J u m l a h (n) & Presentase (\%) \\
\hline PP 1.1.3.1 Dinas Kesehatan & 1.051 .123 .700 & 43,26 \\
PP 1.1.3.2 Puskesmas & 1.378 .786 .516 & 56,74 \\
\hline T o t a l & 2.429 .910 .216 & 100,00 \\
\cline { 2 - 3 }
\end{tabular}

Sumber: Data Dinas Kesehatan Kabupaten Badung Tahun 2019

Tabel 2 memperlihatkan puskesmas mendapat porsi anggaran pencegahan stunting lebih besar $(56,74 \%)$ dibandingkan dengan Dinas Kesehatan $(43,26 \%)$.

Tabel 3 Analisa Belanja Kesehatan Program Pencegahan Stunting Menurut Jenis Kegiatan Tahun Anggaran 2018

Kegiatan Langsung (Ha) $\quad$ Jumlah (n) $\quad$ Presentase (\%)




\begin{tabular}{|c|c|c|}
\hline \multicolumn{3}{|l|}{ HA.2.1. Program Upaya Kesehatan } \\
\hline Masyarakat & 1.925.580.960 & 65,62 \\
\hline $\begin{array}{l}\text { HA.2.1.1. Promosi dan Penyuluhan } \\
\text { Kesehatan }\end{array}$ & 378.450 .000 & 12,90 \\
\hline $\begin{array}{l}\text { HA.2.1.11. Pengadaan dan Pemeliharaan } \\
\text { Alat Medis }\end{array}$ & 499.764 .100 & 17,03 \\
\hline $\begin{array}{l}\text { HA.2.1.13. Upaya Kesehatan Masyarakat } \\
\text { Lainnya }\end{array}$ & 430.000 .000 & 14,65 \\
\hline HA.2.1.4. Pendataan Sasaran & 201.205 .000 & 6,86 \\
\hline HA.2.1.5. Pengambilan Sampel & 155.071 .860 & 5,28 \\
\hline HA.2.17.. Surveilans Gizi & 261.090 .000 & 8,90 \\
\hline \multicolumn{3}{|l|}{ HA.2.2. Program Upaya Kesehatan } \\
\hline Perorangan & 250.700 .556 & 8,54 \\
\hline HA.2.2.4. Rehabilitasi Medik & 250.700 .556 & 8,54 \\
\hline Kegiatan Tak Langsung & 253.628 .700 & 8,64 \\
\hline HA.1.2. Peningkatan Kapasitas Petugas & 253.628 .700 & 8,64 \\
\hline Tot a l & 2.934 .239 .472 & 100,00 \\
\hline
\end{tabular}

Sumber: Data Dinas Kesehatan Kabupaten Badung Tahun 2019

Dari tabel 3 dapat dilihat bahwa biaya program pencegahan stunting sebagian besar digunakan untuk kegiatan langsung $(65,62 \%)$, sedangkan kegiatan tidak langsung hanya $8,64 \%$.

Tabel 4 Analisa Belanja Kesehatan Program Pencegahan Stunting Menurut Mata Anggaran Tahun Anggaran 2018

\begin{tabular}{lrc}
\hline \multicolumn{1}{c}{ Mata Anggaran (Hi) } & Jumlah (n) & Presentase (\%) \\
\hline HI.1. Investasi & & \\
HI.1.4. Pengadaan Alat medis & 499.764 .100 & 20,57 \\
\hline HI.2. Operasional & & \\
HI.2.2. Honorarium & 63.250 .000 & 2,60 \\
HI.2.3. Obat dan Bahan Medis & 455.071 .860 & 18,73 \\
HI.2.4. Bahan Non-Medis & 1.330 .700 .556 & 54,76 \\
HI.2.5.Perjalanan & 53.365 .787 & 2,20 \\
HI.2.6.Akomodasi & 27.757 .913 & 1,14 \\
\hline \multicolumn{1}{c}{ Total } & 2.429 .910 .216 & 100,00 \\
\hline
\end{tabular}

Sumber: Data Dinas Kesehatan Kabupaten Badung Tahun 2019

Dari tabel 4 dapat dilihat bahwa belanja program pencegahan stunting sebagian besar dipergunakan untuk belanja yang bersifat operasional (79,43\%). Biaya operasional terbanyak adalah bahan non-medis $(54,76 \%)$ dan pengadaan obat serta bahan medis $(18,73 \%)$. 
Tabel 5 Analisa Belanja Kesehatan Program Pencegahan Stunting Menurut Jenjang Kegiatan Tahun Anggaran 2018

\begin{tabular}{|c|c|c|}
\hline Jenjang Kegiatan (Hi) & Jumlah (n) & Presentase $(\%)$ \\
\hline HL.2. Provinsi & 211.090 .556 & 8,69 \\
\hline HL.3. Kabupaten & 708.609 .900 & 29,16 \\
\hline HL.3. Kecamatan/Puskesmas & 1.401 .274 .260 & 57,67 \\
\hline HL.4. Desa/Kelurahan/Masyarakat & 108.935 .500 & 4,48 \\
\hline Total & 2.429 .910 .216 & 100,00 \\
\hline
\end{tabular}

Sumber: Data Dinas Kesehatan Kabupaten Badung Tahun 2019

Pada tabel 5 dapat dilihat bahwa jenjang kegiatan paling banyak pada tingkat Kecamatan/Puskesmas (57,67\%), sedangkan yang paling rendah jenjang kegiatan ada pada tingkat Desa/Kelurahan/Masyarakat (4,48\%).

Tabel 6 Analisa Belanja Kesehatan Program Pencegahan Stunting Menurut Penerima Manfaat Tahun Anggaran 2018

\begin{tabular}{llrc}
\hline \multicolumn{1}{c}{ Penerima Manfaat (Hb) } & Jumlah $(\mathbf{n})$ & Presentase $(\%)$ \\
\hline HB.1 & 0 - <1 tahun (bayi) & 72.411 .320 & 2,98 \\
HB.2 & $1-5$ tahun (balita) & 601.888 .760 & 24,77 \\
HB.3 & $6-12$ tahun (anak sekolah) & 50.785 .146 & 2,09 \\
HB.5 & $19-64$ tahun (usia produktif) & 525.589 .570 & 21,63 \\
HB.7 & Semua Kelompok Umur & 1.179 .235 .420 & 48,53 \\
\hline \multicolumn{2}{c}{ Total } & 2.429 .910 .216 & 100
\end{tabular}

Sumber: Data Dinas Kesehatan Kabupaten Badung Tahun 2019.

Tabel 6 menunjukan pembiayaan kesehatan terutama diarahkan pada semua kelompok umur $(48,53 \%)$, balita $(24,77 \%)$ dan kelompok usia produktif $(21,63 \%)$.

\section{Analisa Pola Belanja Rumah Tangga}

Berdasarkan data Indikator Kesejahteraan Rakyat Kabupaten Badung Tahun 2018 yang dikeluarkan oleh Badan Pusat Statistik Kabupaten Badung, rata- 
rata pengeluaran per kapita per bulan masyarakat Kabupaten Badung menurut kelompok komoditas dan kelompok pengeluaran dapat dilihat pada tabel 7.

Pada tabel 7 dan 8, dapat dilihat bahwa rata-rata pengeluaran per bulan masyarakat Kabupaten Badung untuk kebutuhan makanan sebanyak Rp. 725.574 atau setara dengan mengkonsumsi makanan sebanyak 2.232,56 Kcal per orang per hari

Tabel 7 Rata-Rata Pengeluaran per Kapita per bulan menurut Kelompok Komoditas dan Kelompok Pengeluaran Tahun 2018

\begin{tabular}{|c|c|c|c|c|}
\hline \multirow[b]{2}{*}{ Kelompok Komoditas } & \multicolumn{3}{|c|}{ Kelompok Pengeluaran (rupiah) } & \multirow{2}{*}{$\begin{array}{c}\text { Rata - } \\
\text { Rata }\end{array}$} \\
\hline & $\begin{array}{l}40 \text { Persen } \\
\text { Terbawah }\end{array}$ & $\begin{array}{l}40 \text { Persen } \\
\text { Tengah }\end{array}$ & $\begin{array}{l}20 \text { Persen } \\
\text { Teratas }\end{array}$ & \\
\hline (2) & $(3)$ & (4) & $(5)$ & $(6)$ \\
\hline Makanan dan minuman & 438.944 & 802.793 & 1.141 .944 & 725.574 \\
\hline Perumahan dan fasilitas & 256.173 & 593.255 & 1.320 .906 & 604.406 \\
\hline Aneka barang dan jasa & 76.215 & 183.152 & 456.932 & 195.277 \\
\hline $\begin{array}{l}\text { Pakaian, alas kaki, dan tutup } \\
\text { kepala }\end{array}$ & 13.760 & 33.841 & 66.660 & 32.400 \\
\hline Barang tahan lama & 13.215 & 49.391 & 474.510 & 119.992 \\
\hline $\begin{array}{l}\text { Pajak, pungutan, dan } \\
\text { asuransi }\end{array}$ & 31.724 & 70.145 & 160.628 & 72.925 \\
\hline $\begin{array}{l}\text { Keperluan pesta dan } \\
\text { upacara/kenduri }\end{array}$ & 44.349 & 96.772 & 152.759 & 87.071 \\
\hline
\end{tabular}

Sumber: Data Dinas Kesehatan Kabupaten Badung Tahun 2019.

Tabel 8 Rata-Rata Konsumsi Kalori per Kapita Sehari menurut Kelompok Komoditas Makanan dan Kelompok Pengeluaran (Kcal) Tahun 2018

\begin{tabular}{ccccc}
\hline \multirow{2}{*}{$\begin{array}{c}\text { Kelompok } \\
\text { Komoditas }\end{array}$} & $\begin{array}{c}\text { 40 Persen } \\
\text { Terbawah }\end{array}$ & $\begin{array}{c}\text { Kelompok } \\
\text { Komoditas }\end{array}$ & $\begin{array}{c}\text { 20 Persen } \\
\text { Teratas }\end{array}$ & $\begin{array}{c}\text { Rata }- \\
\text { rata }\end{array}$ \\
\hline (1) & $(2)$ & $(3)$ & $(4)$ & $(5)$ \\
\hline \hline & \multicolumn{4}{c}{ Kelompok Pengeluaran } \\
\hline \multicolumn{4}{c}{ Jurnal Kesehatan Mledika Udayana Vol.06 No.01 April 2020 } & Page 59
\end{tabular}




\begin{tabular}{lrrrr}
\hline Padi-padian & 796,43 & 821,94 & 708,71 & 789,12 \\
Umbi-umbian & 22,85 & 22,86 & 21,16 & 22,52 \\
Ikan/udang/cumi/ & 34,65 & 43,35 & 46,64 & 40,54 \\
Daging & 87,59 & 142,72 & 150,26 & 122,25 \\
Telur dan susu & 43,34 & 59,73 & 83,22 & 57,89 \\
Sayur-sayuran & 37,18 & 42,16 & 44,77 & 40,7 \\
Kacang-kacangan & 51,43 & 65,56 & 57,59 & 58,33 \\
Buah-buahan & 41,14 & 64,16 & 81,73 & 58,5 \\
Minyak dan kelapa & 196,56 & 220,62 & 231,01 & 213,11 \\
Bahan minuman & 66,76 & 78,06 & 75,27 & 72,99 \\
Bumbu-bumbuan & 8,62 & 11,88 & 13,76 & 10,96 \\
Konsumsi lainnya & 32,77 & 50,57 & 65 & 46,36 \\
Makanan dan & 543,24 & 732,2 & 944,32 & 699,3 \\
minuman & 0 & 0 & 0 & 0 \\
Rokok dan tembakau & $\mathbf{9 6 2 , 5 5}$ & $\mathbf{2 . 3 5 5 , 8 0}$ & $\mathbf{2 . 5 2 3 , 4 4}$ & $\mathbf{2 . 2 3 2 , 5 6}$ \\
\hline Jumlah Konsumsi & $\mathbf{1 . 9 6 , 5 3}$
\end{tabular}

Sumber: Data Dinas Kesehatan Kabupaten Badung Tahun 2019

\section{PEMBAHASAN}

Pembiayaan program pencegahan stunting hanya bersumber dari pemerintah, dan biaya terbanyak bersumber dari pemerintah pusat. Peran pemerintah pusat sangat besar dalam upaya menurunkan angka stunting di Kabupaten Badung. Masalah stunting memang banyak berkaitan dengan komitmen global serta nasional sehingga banyak luncuran anggaran dari pusat. Selama ini alokasi anggaran pemerintah kabupaten lebih tertuju pada kegiatan fisik dalam bentuk obat, bahan dan alat habis pakai, tanah, rehabilitasi dan pembangunan sarana kesehatan. Pemerintah daerah harus mulai mempertimbangkan dana riil untuk pencegahan stunting karena jika anggaran dari pusat berkurang, maka pembiayaan akan beralih ke pemerintah daerah (Rahmaniawati, 2007).

Berdasarkan alokasinya, puskesmas mendapat porsi anggaran pencegahan stunting lebih besar (56,74\%) dibandingkan dengan Dinas Kesehatan (43,26\%). Pembagian ini dianggap wajar karena puskesmas merupakan unit pelayanan kesehatan untuk publik. UU No 36 tahun 2009 tentang kesehatan mengatur besaran anggaran kesehatan pusat adalah 5 persen dari APBN di luar gaji, sedangkan APBD Propinsi dan Kab/Kota 10 persen di luar gaji, dengan peruntukannya 2/3 untuk 
pelayanan public (Gobel, 2015). Anggaran program pencegahan stunting yang dikelola oleh di puskesmas diutamakan untuk upaya promotif dan preventif seperti penyuluhan gizi, pemberian tablet tambah darah untuk ibu hamil, pemberian vitamin A dan makanan tambahan untuk balita, sedangkan Dinas Kesehatan Kabupaten Badung menggunakan anggaran program pencegahan stunting untuk advokasi, koordinasi dan peningkatan kapasitas petugas kesehatan.

Program pencegahan stunting lebih di dominasi oleh kegiatan langsung $(65,62 \%)$, dibandingkan kegiatan tidak langsung (8,64\%). Contoh kegiatan langsung adalah kegiatan pemberian pemberian makanan tambahan dan makanan pendamping air susu ibu untuk perbaikan gizi balita. Namun demikian, komponen kegiatan langsung masih didominasi oleh kegiatan pengadaan dan pemeliharaan alat medis (Rp.499 juta lebih) yang jauh lebih besar dibandingkan dengan kegiatan promosi dan penyuluhan kesehatan yang berjumlah Rp.378 juta lebih. Kegiatan promosi dan penyuluhan kesehatan haruslah menjadi fokus utama karena kegiatan ini mendorong peran serta dan partisipasi masyarakat untuk hidup sehat secara mandiri dalam memenuhi kebutuhan gizi keluarganya. Hal ini sesuai dengan kebijakan kementerian kesehatan Republik Indonesia akan mengambil kebijakan untuk mengembalikan fungsi puskesmas sebagai fasilitas kesehatan dengan konsentrasi pelayanan pada upaya promotif dan preventif yang antara lain mencakup edukasi kesehatan serta pencegahan dan deteksi dini penyakit (Arby, 2019).

Program pencegahan stunting sebagian besar untuk kegiatan yang bersifat operasional. Biaya operasional terbanyak untuk membeli bahan non-medis $(54,76 \%)$ dan pengadaan obat serta bahan medis $(18,73 \%)$. Bahan yang termasuk non medis antara lain; bahan bakar minyak untuk kegiatan promotif dan preventif di luar gedung puskesmas, alat tulis kantor, bahan makanan untuk penyuluhan gizi. Sedangkan yang termasuk obat dan bahan medis antara lain; tablet tambah darah, vitamin A, obat cacing dan bahan penunjang medis untuk perawatan pasien.

Secara berjenjang, kegiatan paling banyak pada dilakukan pada tingkat Kecamatan/Puskesmas $(57,67 \%)$, sedangkan yang paling rendah jenjang kegiatan 
ada pada tingkat Desa/Kelurahan/Masyarakat (4,48\%). Puskesmas merupakan fasilitas layanan kesehatan terdepan yang memiliki tiga fungsi sebagai lembaga pertama dan utama dalam memberikan pelayanan peningkatan kesehatan, pencegahan penyakit, pengobatan dan pemulihan, memberdayakan keluarga dan menjadi pusat informasi kesehatan bagi keluarga maupun anak dan memberi dukungan agar mereka dapat mempraktekkan pengetahuan kesehatan dalam kehidupan. Oleh karena puskesmas memiliki banyak peran dan fungsi dalam pembangunan kesehatan, maka puskesmas harus didukung dengan anggaran yang cukup agar mampu melaksanakan fungsinya secara efektif (Mustakim, 2017).

Berdasarkan penerima tertinggi dari kelompok umur (48,53\%) lalu diikuti oleh kelompok balita $(24,77 \%)$ serta kelompok usia produktif $(21,63 \%)$. Untuk mempercepat pencegahan stunting, Kementerian Kesehatan menetapkan sasaran prioritas antara lain; ibu hamil, ibu menyusui, dan anak berusia 0-23 bulan (1.000 hari pertama kelahiran melalui upaya perbaikan gizi ibu hamil dan peningkatan status gizi anak. Pembiayaan kesehatan untuk program pencegahan stunting ditujukan pada kelompok umur 0-5 tahun yang memegang peranan kunci bagi tercapaianya pembangunan kesehatan di masa depan (Ascobat Gani, 2000).

Rata-rata pengeluaran per bulan masyarakat Kabupaten Badung untuk kebutuhan makanan sebanyak Rp. 725.574 atau setara dengan mengkonsumsi makanan sebanyak 2.232,56 Kcal per orang per hari. Angka ini sudah memenuhi angka rata-rata kecukupan kalori masyarakat yang ditetapkan oleh Kementerian Kesehatan Republik Indonesia yaitu antara 2.200-2.500 Kcal per orang per hari. Bila diperhatikan secara lebih detail, pada kelompok masyarakat $40 \%$ terbawah (keluarga miskin) rata-rata pengeluaran per bulan sebanyak Rp.438.944 atau setara dengan mengkonsumsi makanan sebanyak 1.962,55 Kcal per orang per hari (di bawah batas minimum). Menurut Yuliana (2017), pertumbuhan ekonomi yang negative berdampak terhadap penurunan laju pertumbuhan, ekonomi akan menyebabkan perubahan yang terjadi pada pemutusan hubungan kerja, semakin meningkat tingkat pencapaian dan pada akhirnya akan mening- per katkan jumlah penduduk miskin, putaran pendapatan keluarga, ek «dan peningkatan daya beli 
terhadap bun makanan dan kesehatan jadi dicelupkan tidak terpenuhinya ka konsumsi makanan dan har pada akhirnya meningkatkan masalah gizi (gizi buruk pada balita). Demikian pula dengan hasil penelitian Handini, dkk, (2013) di wilayah kerja Puskesmas Kalijambe menyimpulkan bahwa terdapat hubungan antara tingkat pendapatan keluarga dengan status gizi balita.

Diperlukan adanya proses pemantauan dan evaluasi untuk penyempurnaan program pencegahan stunting ke depan, baik dalam proses perencanaan dan penganggaran terkait dengan proses identifikasi output, proses pelaksanaan serta evaluasi atas konvergensi yang terjadi dalam pelaksanaan seluruh proses pembiayaan. Dengan demikian diperlukan upaya perbaikan yang dapat meningkatkan kualitas pembiayaan dalam penanganan permasalahan stunting serta kualitas pembiayaan secara umumnya.

\section{SIMPULAN DAN SARAN}

Berdasarkan data Dinas Kesehatan Provinsi Bali, angka stunting di Kabupaten Badung pada tahun 2015 sebanyak 13,6\% lalu menurun menjadi 11,5\% pada tahun 2016. Memasuki tahun 2017 angka stunting kembali meningkat mencapai $25,24 \%$. Biaya program pencegahan stunting hanya bersumber dari pemerintah, dimana biaya terbanyak bersumber dari pemerintah pusat $(70,16 \%)$, jauh melebihi Pemerintah Kabupaten Badung $(21,16 \%)$ dan Pemerintah Provinsi Bali $(8,69 \%)$. Porsi anggaran pencegahan stunting puskesmas lebih besar $(56,74 \%)$ dibandingkan dengan Dinas Kesehatan (43,26\%). Dimana sebagian besar pembiayaan dipergunakan untuk belanja yang bersifat operasional $(79,43 \%)$. Pembiayaan pencegahan stunting terutama diarahkan pada semua kelompok umur $(48,53 \%)$, balita $(24,77 \%)$ dan kelompok usia produktif $(21,63 \%)$.

Rata-rata pengeluaran per bulan masyarakat Kabupaten Badung untuk kebutuhan makanan sebanyak Rp.725.574 atau setara dengan mengkonsumsi makanan sebanyak 2.232,56 Kcal per orang per hari. Khusus pada kelompok masyarakat $40 \%$ terbawah (keluarga miskin) rata-rata pengeluaran per bulan hanya sebanyak Rp.438.944 atau setara dengan mengkonsumsi makanan sebanyak 
1.962,55 Kcal per orang per hari (di bawah batas minimum), angka ini di bawah angka rata-rata kecukupan kalori masyarakat yang ditetapkan oleh Kementerian Kesehatan Republik Indonesia yaitu antara 2.200 - 2.500 Kcal per orang per hari.

Pembiayaan program pencegahan stunting di Kabupaten Badung perlu ditingkatkan, agar pembiayaan bersumber APBD Kabupaten Badung jumlahnya seimbang dengan sumber pembiayaan dari APBN. Agar peran serta masyarakat meningkat dalam program pencegahan stunting, maka proporsi pembiayaan untuk upaya promotif dan preventif perlu ditingkatkan sampai batas optimal. Pembiayaan program pencegahan stunting agar lebih diprioritaskan kepada penduduk $40 \%$ terbawah (penduduk miskin), sehingga kebutuhan konsumsi kalorinya tercukupi sesuai standard yang ditetapkan (2.200-2.500 Kcal per orang per hari).

\section{DAFTAR PUSTAKA}

Arby. (2019). Puskesmas Didorong Fokus ke Layanan Promotif-Preventif. Diakses dari: $\quad$ https://m.harianterbit.com/read/112302/Puskesmas-DidorongFokus-ke-Layanan-Promotif-Preventif. Pada tanggal; 13 Januari 2020.

Dewi, Bestari Kumala. (2017). Mengenal "Stunting" dan Efeknya pada Pertumbuhan Anak. Diakses dari : https://ifestyle.kompas.com/read/2017/02/08/100300123/mengenal.stunti ng. dan.efeknya. pada.pertumbuhan.anak?page=all. Pada tanggal 16 Desember 2019.

Dinkes Prov. Bali. (2019). Profil Dinas Kesehatan Provinsi Bali Tahun 2018.

Fatimah, Nabilla Siti Hawa. (2018). Tingkat Kecukupan Vitamin A, Seng Dan Zat Besi Serta Frekuensi Infeksi Pada Balita Stunting Dan Non Stunting. Diakses dari : https://media.neliti.com/media/publications/152719-IDdefisiensi-vitamin-a-dan-zinc-sebagaifak.pdf. Pada tanggal 17 Desember 2019.

Gani, A. (2009). Pedoman dan Modul Pelatihan District Health Account (DHA) untuk Tingkat Kabupaten dan Kota, Pusat Pembiayaan dan Jaminan. Jakarta: Kesehatan Depkes RI

Gobel, Fatmah Afrianty. (2015). Kebijakan Pembiayaan Kesehatan, Diakses dari: https://www.kompasiana.com/yantigobel/550ee41ca33311b92dba8544/ke bijakan-pembiayaan-kesehatan. Pada tanggal; 13 Januari 2020. 
Handini, Dian, dkk. (2013). Hubungan Tingkat Pendapatan Keluarga Dengan Status Gizi Balita Di Wilayah Kerja Puskesmas Kalijambe, Fakultas Kedokteran, Universitas Muhammadiyah Surakarta. Diakses dari: http://eprints.ums.ac.id/24014/9/naskah_publikasi.pdf. Pada tanggal; 13 Januari 2020.

Kemenkes RI. (2019). Riset Kesehatan dasar Tahun 2018.

Mustakim. (2017). Puskesmas Fasilitas Pelayanan Kesehatan Terdepan. Diakses dari: http://infopublik.id/read/227709/puskesmas-fasilitas-pelayanankesehatan-terdepan.html. Pada tanggal; 13 Januari 2020.

Novianto, Hedi,(2019). Angka stunting turun, tapi belum standar WHO. Diakses dari : https://beritagar.id/artikel/berita/angka-stunting-turun-tapi-belumstandar-who. Pada tanggal 16 Desember 2019.

Rahmaniawati, Nia Aryani. (2007). Analisis Pembiayaan Kesehatan Bersumber Pemerintah di Kabupaten Bogor. KESMAS. Jurnal Kesehatan Masyarakat Nasional Vol. 2, No. 1, Agustus 2007

Satriawan, Elan. (2018). Strategi Nasional Percepatan Pencegahan Stunting 20182024. Pokja Kebijakan Tim Nasional Percepatan Penanggulangan Kemiskinan (TNP2K) Sekretariat Wakil Presiden Republik Indonesia. Diakses dari http://tnp2k.go.id/filemanager/files/ Rakornis\%202018/Sesi\%201_01_RakorStuntingTNP2K_Stranas_22Nov2 018.pdf. Pada tanggal 16 Desember 2019.

Yuliana. (2017). Keterkaitan Antara Pertumbuhan Ekonomi, Kemiskinan, dan Status Gizi Balita Di Indonesia. Diakses dari: http://jurnaldikbud.kemdikbud.go.id/index.php/jpnk/ article/ view/337. Pada tanggal; 13 Januari 2020. 